\title{
Perceptions of Social Responsibility of Prominent Fast Food Restaurants
}

\author{
Carissa J. Morgan1, Nicole Olynk Widmar ${ }^{1 *}$, Elizabeth A. Yeager ${ }^{2}$, W. Scott Downey ${ }^{1}$, \\ Candace C. Croney ${ }^{3}$ \\ ${ }^{1}$ Department of Agricultural Economics, Purdue University, West Lafayette, IN, USA \\ ${ }^{2}$ Department of Agricultural Economics, Kansas State University, Manhattan, KS, USA \\ ${ }^{3}$ College of Veterinary Medicine, Purdue University, West Lafayette, IN, USA \\ Email: "nwidmar@purdue.edu
}

Received 12 May 2016; accepted 11 June 2016; published 15 June 2016

Copyright (C) 2016 by authors and Scientific Research Publishing Inc.

This work is licensed under the Creative Commons Attribution International License (CC BY).

http://creativecommons.org/licenses/by/4.0/

\section{(c) (i) Open Access}

\section{Abstract}

In this study, U.S. resident's perceptions of social responsibility of prominent fast food restaurants were investigated. A survey conducted in April 2015 collected information from a sample targeted to be representative of the U.S. population. In total, 302 completed participant's responses were analyzed ( $\mathrm{n}=302$ ). Using a best-worst choice experiment question, participant's choices for "most" and "least" socially responsible fast food restaurants were analyzed, resulting in individual's relative perceptions of social responsibility amongst the restaurants studied. Results indicate that of the fast food restaurants studied, Panera Bread was perceived to be the most socially responsible restaurant, followed by Subway and Chick-fil-A. In contrast, McDonald's, KFC, and Taco Bell were perceived to be the least socially responsible of the fast food restaurants studied. Additionally, relationships amongst participant's perceptions of social responsibility in fast food, demographic factors, consumption practices, and knowledge of fast food business practices were analyzed. Significant relationships were found amongst "being female" and "self-reported knowledge of fast food business practices" with "perceptions of the social responsibility of fast food restaurants".

\section{Keywords}

Fast Food, Restaurants, Perceptions, Social Responsibility, Best-Worst Scaling

\section{Introduction}

Keeping focus on the consumer is critical for the fast food industry as well as other customer service firms. In 2014, the average U.S. consumer spent $\$ 2,390$ on food [1]. Consumers are increasingly demanding more from

"Corresponding author.

How to cite this paper: Morgan, C.J., Widmar, N.O., Yeager, E.A., Downey, W.S. and Croney, C.C. (2016) Perceptions of Social Responsibility of Prominent Fast Food Restaurants. Modern Economy, 7, 704-714.

http://dx.doi.org/10.4236/me.2016.76074 
their food, and fast food companies in particular have been trying to meet customers' growing demands for social responsibility. McDonald's [2] is claiming to make sustainable practices the "new normal” for their business while Panera Bread [3] is focusing on "food as it should be" with clean ingredients, menu transparency, and an initiative to make a positive impact on the food system. Despite the efforts of these companies, to our knowledge, no studies have thoroughly examined consumers' perceptions of the social responsibility of fast food companies.

Corporate Social Responsibility (CSR) is not a new topic of discussion. Yet a consistent, objective definition and set of corresponding public expectations remain elusive. Corporate Social Performance (CSP) and the element that is the social responsibility of firms have been examined since the mid-1950's [4]. However, some suggest that it has been practiced in the U.S. since the late 1890's [5]. One early definition of CSR is "the firm's consideration of, and response to, issues beyond the narrow economic, technical, and legal requirements of the firm (to) accomplish social benefits along with the traditional economic gains which the firm seeks” ([6], pp. 312-313). [4] breaks CSR into three principles: legitimacy, public responsibility, and managerial discretion applied at the institutional, organizational, and individual level.

The current movement towards CSR may be influenced by the belief that companies can be more influential and effective in addressing social and environmental issues and the general argument that "good corporate citizenship is also good business" ([7], p. 11). The impact of CSR in the fast food sector may be tied to the ability of restaurants to further differentiate themselves through cause-related marketing [8]. Despite differences in cuisine, the overall quality, price, and service offered by fast food restaurants is often similar. Thus, Bronn and Vrioni [8] warn firms pursuing cause-related marketing as a means of promoting their CSR initiatives that they must first ensure that they are genuine and have a full understanding of their consumers' knowledge, understanding, and potential skepticism.

The customer-perceived value is comprised of tangible attributes and is related to product quality and processing. However, this is increasingly related to less tangible attributes, like brand image and CSR [9] [10]. Key aspects of these intangible attributes (i.e. animal welfare and ethically sourced ingredients) are often important to consumers although they cannot be verified through consumption of the food. Schroeder and Mc Eachern [10] therefore argue that there then become two audiences for CSR initiatives: the consumer of the product and the broader public.

One mixed-methods study from the UK examined the awareness and perceptions of CSR for McDonald's and KFC [10], focusing on students from an English and Scottish university. The majority of fast food purchasing decisions were made on impulse. Exploratory factor analysis was used to identify four central attitudes towards fast food purchase behavior: brand value, nutritional value, ethical value, and food quality [10]. General findings were a high level of awareness of McDonald's CSR initiatives and expectation of the majority of respondents that fast food companies should be involved in healthy eating initiatives, animal welfare, and community activities [10].

The aim of this study was to contribute to knowledge on perceptions of CSR by investigating U.S. resident's perceptions of the "most" and "least" socially responsible of prominent fast food restaurants. The present situation in the U.S. with regard to perceptions of CSR for fast food restaurants is largely unstudied. Nearly all food service establishments portray to their customers aspects of their business which may be interpreted as related to CSR. Information shared can range from nutritional information to procurement strategies (i.e., local or from farms using certain practices) and treatment of employees. However, the presentation of CSR information is such that comparisons across restaurants can be difficult. For example, the language used to describe different aspects of CSR may differ significantly. Further, there is not a central source of information that summarizes CSR activities for all restaurants in an accessible way. The objective of this study was to examine the tradeoffs amongst perceptions of social responsibility of prominent fast food restaurants by utilizing a best-worst scaling estimation of consumer perceptions of CSR of fast food restaurants. Previous studies have used best-worst analysis to investigate perceptions; Cummins et al. [11] sought to understand consumer preferences for "most" and "least" important pork attributes, while Wolf and Tonsor [12] investigated producer's preferences for "most" and "least" important dairy policies. Erdem et al. [13] also used this methodology to examine tradeoffs made by both consumers and producers for relative responsibility in ensuring food safety in the food supply chain. This study sought to investigate the relationships amongst individual preferences for social responsibility of prominent fast food restaurants, participant demographic factors, and consumption practices. 


\section{Materials and Methods}

An online survey was distributed to collect information from 1201 U.S. residents from March $31^{\text {st }}$ through April $4^{\text {th }}$, 2015. The sample was targeted to be representative of the U.S. national population according to the 2012 U.S. Census. Researchers at Purdue University created the survey, and then Light speed GMI distributed a link to potential respondents in their large proprietary opt-in panel. The questionnaire was designed to collect basic demographic information (gender, age, pre-tax income, education, region of residence) in addition to information about monthly food expenditures, fast food consumption habits, and the nature and frequency of their restaurant visits. Respondents were required to be at least 18 years of age to participate in the survey.

Within the survey, a randomly selected subset of participants, $n=302$, was shown a best-worst choice experiment in which they indicated their preference for the "most" and "least" socially responsible fast food restaurants over a series of best-worst scaling (BWS) choice scenarios. Preferences of those respondents $(n=302)$, elicited through the BWS choice experiment were analyzed. All analyses were completed using the sample of respondents who completed the BWS questions $(\mathrm{n}=302)$.

In addition to the BWS, this analysis used cross-tabulations to investigate relationships between monthly fast food consumption and demographic factors, including gender, households with/without children, age, household income, and education level.

\section{Econometric Methodology}

In BWS methodology, participants are forced to make tradeoffs over a series of choice scenarios offering multiple options [14]. Developed by Jordan Louviere in the late 1980's, BWS originated in random utility theory [15]. Also called maximum-difference scaling, BWS outcomes represent the maximum difference between a respondent's most and least preferred options [16]. This study investigated individual perceptions of the "most" and "least" socially responsible fast food restaurants. The eleven fast food restaurants that were presented in this study were (in no particular order): McDonald's, Subway, Panera Bread, Starbucks, Wendy's, Burger King, Taco Bell, Dunkin’ Donuts, KFC, Chick-fil-A, and Chipotle.

In this experiment, participants could choose any one fast food restaurant up to five times. Given that eleven attributes (fast food restaurants) were presented $(j), J=11$ in the experiment, the total possible choice combinations were calculated as: $J(J-1)=110$. In short, there were 110 aggregate possible best-worst choice combinations. Participant selections of the "most" and "least" socially responsible fast food restaurants were used to determine the relative social responsibility of each fast food restaurant presented in this study. These two selections represent the maximum difference between two attributes on the underlying continuum of importance [17]. Similar in form to Lusk and Briggeman's [17] study, participant's latent unobservable level of importance is denoted as: $I_{i j}=\lambda_{j}+\varepsilon_{i j}$, in which $\lambda_{j}$ is used to represent the location of importance for each attribute, $j$ on the continuum of importance, in which the random error term is $\varepsilon_{i j}$.

The probability that a respondent chooses $j$ and $k$, respectively, as the best and worst, or "most" and "least," socially responsible fast food restaurants, is the probability that the difference between $I_{i j}$ and $I_{i k}$ is larger than all other $J(J-1)-1$ possible choice combinations [17], thus represented by the maximum difference between a respondent's two chosen attributes. As in the experiment outlined by Lusk and Briggeman [17], the error term is assumed to be independently and identically distributed. The probability of choosing one attribute as most socially responsible and another attribute as least socially responsible was represented in the multinomial log it (MNL) form:

$$
\text { Prob }(j \text { is chosen most and } k \text { is chosen least })=\frac{\mathrm{e}^{\lambda_{j}-\lambda_{k}}}{\sum_{l=1}^{J} \sum_{m=1}^{J} \mathrm{e}^{\lambda_{l}-\lambda_{m}}-J}
$$

However, the MNL model was hypothesized to not accurately represent participant preferences as it assumes homogenous preferences across attributes. Participant's perceptions of CSR amongst fast food restaurants were hypothesized to be heterogeneous. Studies such as Shwartz [18] and Auger et al. [19], have shown that individual people, even within the same society, can have unique preferences. Therefore, the random parameter logit (RPL) model, which assumes heterogeneous preferences amongst respondents for the presented attributes, was estimated in addition to the MNL. Adjustments from (1) for the RPL model include the unobservable level of importance for respondent $i$ and attribute $j$ in population $\lambda_{j}$, in which the mean is represented as $\bar{\lambda}_{j}$, the standard 
deviation $\sigma_{j}$, and the random term $\mu_{i}$. Adjustments for the RPL model were then specified as: $\tilde{\lambda}_{i j}=\tilde{\lambda}_{j}+\sigma_{j} \mu_{i j}$. The random term, within the RPL model, was normally distributed with mean zero and unit standard deviation; thus the level of importance of CSR attribute $j$ is distributed according to a normal distribution curve [17].

The probability that each fast food restaurant was picked as most important across all eleven restaurants necessarily sums to one. Shares of preference represent the probabilities and were calculated as:

$$
\text { Share }(j)=\frac{\mathrm{e}^{\hat{\lambda}_{j}}}{\sum_{k=1}^{J} \mathrm{e}^{\hat{\lambda}_{1}}}
$$

Shares of preference for all eleven fast food restaurants were calculated using the RPL model. The perceived CSR (relative to all other fast food restaurants presented) for individual-specific RPL parameter estimates were found through maximum likelihood estimation (MLE) using the individual-specific coefficients from the RPL model. Normalizing MLE to 0 prevents the dummy variable trap [17]. Relative perceived importance or individual-specific preference shares were estimated for each of the eleven fast food restaurants for each respondent (using individual-specific parameter estimates). The individual-specific parameter estimates equipped further analysis, specifically correlations between preferences shares and demographic or consumption factors.

\section{Results and Discussion}

Summary demographics for the sample are displayed in Table 1 . Also shown in Table 1 are the census figures, which were targeted proportions for the sample obtained. Thirteen percent of survey participants were between the ages of 18 and 24, 35\% were 25 to 44, 35\% were aged 45 to 64 , and $17 \%$ were 65 years and older. For analysis purposes, respondent household incomes were grouped into low (less than $\$ 25,000$ to $\$ 34,999$ ), medium ( $\$ 35,000$ to $\$ 99,999$ ), and high ( $\$ 100,000$ to $\$ 150,000$ or higher) income categories; in this sample, 33\% classified as low, $46 \%$ medium, and $21 \%$ high income earning households. Information about geographic region of residence was also collected. In total, $18 \%$ of respondents were from Northeast, $41 \%$ from the South, $20 \%$ from the Midwest, and 21\% from the West. In terms of age, household income, and region of residence, the proportion of the sample in each bracket or category was extremely close to those targeted from the U.S. Census.

Information was also collected from respondents with respect to their education levels, revealing that $57 \%$ of respondents graduated with a higher education degree (Associates, Trade, Bachelors, Masters, or $\mathrm{PhD}$ ). The sample in this study was more educated than the U.S. population overall, which could be due to a number of factors including internet access, available time online, ability to read and/or comprehend, and interest in voluntary participation. The majority of respondents, $68 \%$, did not have children in their household. The information regarding household composition is particularly pertinent when investigating food consumption habits, as having children in the household is believed to influence attitudes toward food and consumption practices. Information regarding respondent/household vegetarian and vegan dietary preferences was also collected. The majority of respondents claimed neither that they nor any member of their household was vegan or vegetarian $(78 \%$ and $79 \%$, respectively).

The knowledge of respondents with respect to fast food operations was of interest, given the focus of this analysis on perceptions of fast food restaurants' perceived responsibility. Responses on questions pertaining to fast food, knowledge of the related business practices, and consumption habits and summary statistics are presented in Table 2. With respect to business practices in fast food, $45 \%$ of respondents self-reported being unknowledgeable, compared to $31 \%$ of respondents who indicated they were knowledgeable.

In addition to an individual's perceived level of knowledge, the consumption behaviors of respondents were of interest, specifically, individual perceptions of fast food with respect to food consumption practices. Respondents were asked about average household weekly food expenditures; $23 \%$ spent less than $\$ 50 /$ week, 34\% spent $\$ 51$ - 100/week, 30\% spent \$101 - \$200/week, while the remaining 12\% spent more than $\$ 200 /$ week. On average, respondents indicated spending $75.8 \%$ of their food budget on food consumed at home and the remaining $24.2 \%$ on food consumed away from home. To gain further insight into spending on food away from home, respondents were asked the average number of times they visited different restaurant types (Figure 1). Restaurant types presented to respondents were: fast food/sit down in restaurant, fast food/take out or drive through, fast casual, casual dining, and fine dining. Most pertinent to this study was people's fast food consumption habits. With respect to fast food/sit down in restaurant eating, the largest portion of respondents, $39 \%$, claimed they did not eat 
Table 1. Sample demographics $(n=302)$.

\begin{tabular}{|c|c|c|}
\hline Variable Description & Survey (\% of respondents) & Census (\% of population) \\
\hline Female & 47 & 51 \\
\hline \multicolumn{3}{|l|}{ Age } \\
\hline 18 to 24 years & 13 & 13 \\
\hline 25 to 44 years & 35 & 35 \\
\hline 45 to 64 years & 35 & 35 \\
\hline 65 years and over & 17 & 17 \\
\hline \multicolumn{3}{|l|}{$\underline{\text { Household Income }}$} \\
\hline Less than $\$ 25,000$ & 24 & 23 \\
\hline$\$ 25,000-\$ 34,999$ & 9 & 11 \\
\hline$\$ 35,000$ - \$49,999 & 11 & 14 \\
\hline$\$ 50,000-\$ 74,999$ & 20 & 18 \\
\hline$\$ 75,000$ - \$99,999 & 15 & 12 \\
\hline$\$ 100,000$ - \$149,999 & 12 & 13 \\
\hline$\$ 150,000$ or more & 9 & 9 \\
\hline \multicolumn{3}{|l|}{$\underline{\text { Region }}$} \\
\hline Northeast & 18 & 18 \\
\hline South & 41 & 38 \\
\hline Midwest & 20 & 22 \\
\hline West & 21 & 22 \\
\hline \multicolumn{3}{|l|}{$\underline{\text { Education }}$} \\
\hline Did not graduate from high school & 2 & \\
\hline $\begin{array}{l}\text { Graduated from high school } \\
\text { did not attend college }\end{array}$ & 17 & \\
\hline Attended college, no degree earned & 22 & \\
\hline $\begin{array}{l}\text { Attended college, associate } \\
\text { or trade degree earned }\end{array}$ & 14 & \\
\hline $\begin{array}{l}\text { Attended college, bachelor's } \\
\text { (B.S. or B.A.) degree earned }\end{array}$ & 27 & \\
\hline $\begin{array}{l}\text { Attended college, advanced } \\
\text { (M.S., Ph.D., Law School) degree earned }\end{array}$ & 16 & \\
\hline Other & 2 & \\
\hline \multicolumn{3}{|l|}{$\underline{\text { Children }}$} \\
\hline Households with & 32 & \\
\hline Households without & 68 & \\
\hline \multicolumn{3}{|l|}{ Vegetarian (\% of responses) } \\
\hline I or a member of my household is & 14 & \\
\hline A close friend or family member is & 14 & \\
\hline No, neither I nor anyone I know is & 78 & \\
\hline \multicolumn{3}{|l|}{ Vegan (\% of responses) } \\
\hline I or a member of my household is & 8 & \\
\hline A close friend or family member is & 11 & \\
\hline No, neither I nor anyone I know is & 79 & \\
\hline \multicolumn{3}{|l|}{$\begin{array}{l}\text { Self-reported knowledge of } \\
\text { business practices in fast food }\end{array}$} \\
\hline Unknowledgeable & 45 & \\
\hline Neutral & 24 & \\
\hline Knowledgeable & 31 & \\
\hline
\end{tabular}


Table 2. Participant spending on food $(n=302)$.

\begin{tabular}{ccc}
\hline & Percent of sample & Average dollars \\
\hline Average weekly spending on food (percentage of sample respondents) & & 23 \\
$\$ 1-50$ & 34 & 36.42 \\
$\$ 51-100$ & 12 & 88.92 \\
$\$ 101-200$ & 100 & 374.19 \\
$\$ 201-1000$ & & 134.36 \\
All categories & 75.8 & - \\
Percent of spending (sample average) & 24.2 & - \\
On food consumed at home &
\end{tabular}

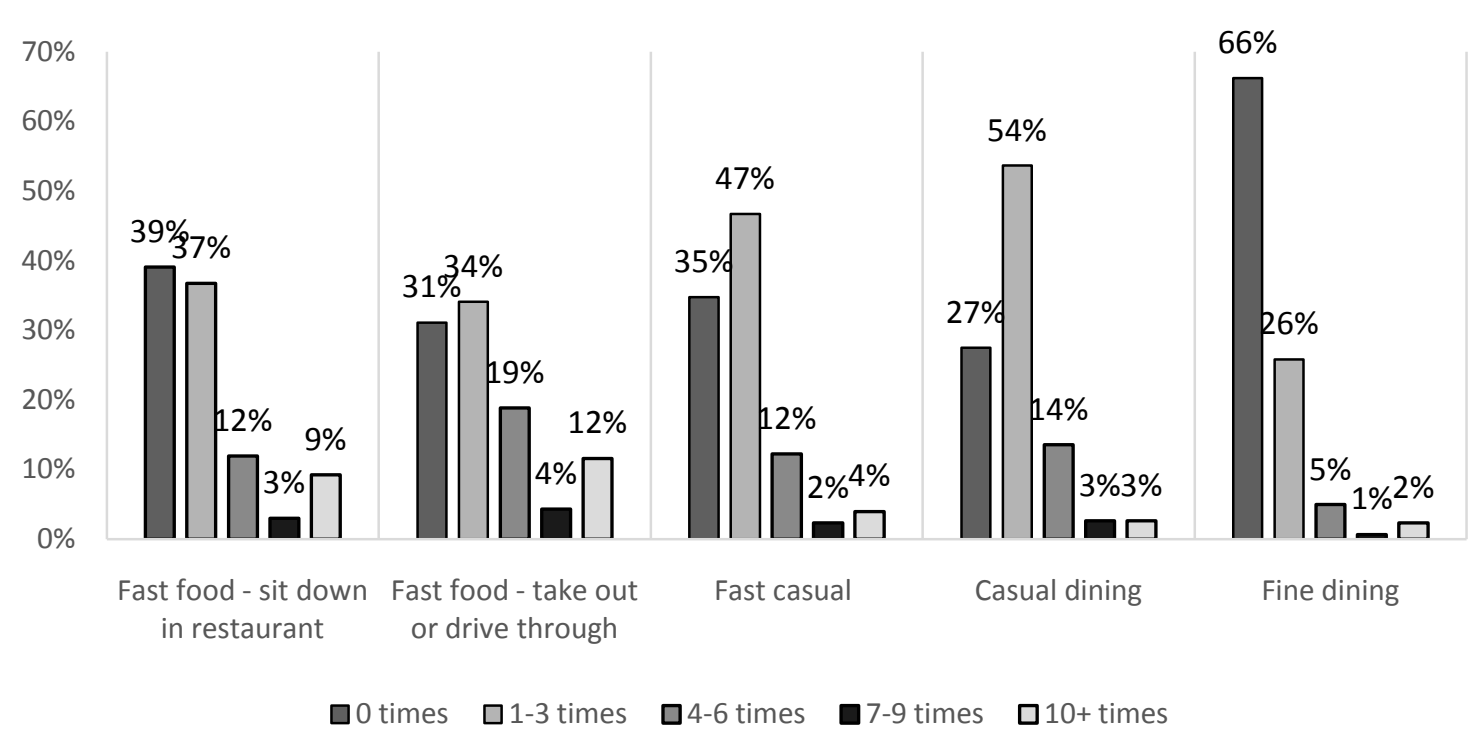

Figure 1. Percent of participants eating at different restaurant types at given frequencies (per month) $(\mathrm{n}=302)$.

at any such establishments in a given month, while 32\% claimed to eat at such restaurants 1 - 3 times monthly, 12\% claimed 4 - 6 monthly visits, 3\% indicated 7 - 9 visits, and 9\% ate fast food more than 10 times per month. Fast food/take out or drive through figures were not practically different as $31 \%$ claimed not to eat any take out fast food in a given month, 34\% ate take out fast food 1 - 3 times per month, 19\% ate takeout fast food 4 - 6 times per month, $4 \%$ ate take out 7 - 9 times per month, and $12 \%$ ate at such establishments more than 10 times per month. Nearly half of participants, 47\%, claimed to eat at fast casual restaurants 1 - 3 times per month, while $35 \%$ did not do so at all, $12 \%$ ate at such restaurants 4 - 6 times monthly, 2\% partook 7 - 9 times per month, and $4 \%$ ate fast casual food more than 10 times per month.

Few differences were observed between males and females for monthly restaurant visits (Table 3). A significantly larger percentage of women visited a fast food restaurant for take-out or went through the drive through 1 - 3 times per month compared to men, who had a larger percentage of fast food restaurant or drive through visits for take-out 4 - 6 times per month. Not surprisingly, households with children frequented fast food take out or drive through options more frequently than households without children. The percentage of respondents who reported no visits in a month was $37.1 \%$ for households without children compared to $18.6 \%$ with children. The percentage of those that frequented 10 or more times was $7.8 \%$ for households without children and $19.6 \%$ for those with children. Respondents of different ages (which was often related to having children at home or not) also varied in their visits to fast food restaurants. Over $52 \%$ of respondents 65 years and older had no monthly visits to a fast food restaurant to sit down, for takeout or drive through, or a fast casual restaurant, and less than $2 \%$ of respondents frequented a fast food restaurant 10 or more times in a month. Comparatively, approximately $20 \%$ of respondents in the 25 - 44 year age group reported no visits to a fast food restaurant and almost $20 \%$ of these respondents had 10 or more visits. 
Table 3. Cross-tabulations of participant monthly restaurant visits and sample demographics (\% of respondents; $n=302$ ).

\begin{tabular}{|c|c|c|c|c|c|c|c|c|c|c|c|c|c|}
\hline \multirow{2}{*}{$\begin{array}{c}\text { Monthly } \\
\text { restaurant visits }\end{array}$} & \multicolumn{2}{|c|}{$\underline{\text { Gender }}^{1}$} & \multicolumn{2}{|c|}{$\underline{\text { Children }}^{2}$} & \multicolumn{4}{|c|}{$\mathrm{Age}^{3}$} & \multicolumn{3}{|c|}{ Income $^{4}$} & \multicolumn{2}{|c|}{ Education $^{5}$} \\
\hline & $\begin{array}{l}\text { Е } \\
\frac{0}{\pi} \\
\sum\end{array}$ & 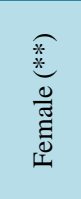 & 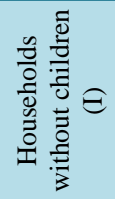 & 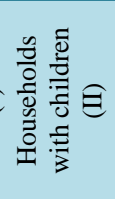 & 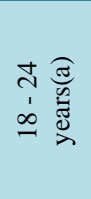 & 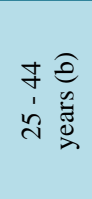 & 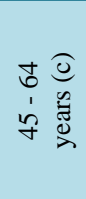 & 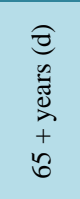 & $\begin{array}{l}\overparen{\Delta} \\
3 \\
0 \\
1\end{array}$ & 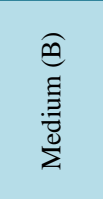 & $\begin{array}{l}0 \\
0 \\
00 \\
0\end{array}$ & 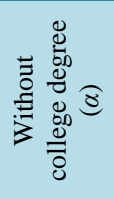 & 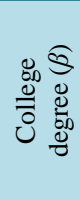 \\
\hline \multicolumn{14}{|l|}{$\begin{array}{l}\text { Fast food } \\
\text {-sit down }\end{array}$} \\
\hline 0 times & 37.1 & 41.3 & $48.3_{\text {II }}$ & 19.6I & 41.0 & $23.1_{\mathrm{c}, \mathrm{d}}$ & $47.7_{\mathrm{b}}$ & $52.9_{\mathrm{b}}$ & $55.0_{\mathrm{B}, \mathrm{C}}$ & $30.9_{\mathrm{A}}$ & $31.7_{\mathrm{A}}$ & $46.2_{\beta}$ & $33.7_{\alpha}$ \\
\hline 1 - 3 times & 34.6 & 39.2 & 34.6 & 41.2 & 28.2 & 43.3 & 31.8 & 41.2 & 33.0 & 41.0 & 33.3 & 35.4 & 37.8 \\
\hline 4 - 6 times & 13.8 & 9.8 & 10.2 & 15.5 & 20.5 & 14.4 & 10.3 & 3.9 & 7.0 & 14.4 & 14.3 & 10.8 & 12.8 \\
\hline 7 - 9 times & $5.0_{* *}$ & $0.7 *$ & $1.0_{\mathrm{II}}$ & $7.2_{\mathrm{I}}$ & 2.6 & 4.8 & 2.8 & 0.0 & $0.0_{\mathrm{C}}$ & 3.6 & $6.3_{\mathrm{A}}$ & $0.8_{\beta}$ & $4.7_{\alpha}$ \\
\hline \multicolumn{14}{|l|}{$\begin{array}{c}\underline{\text { Fast food }} \\
\text {-take out or } \\
\text { drive through }\end{array}$} \\
\hline 0 times & 32.1 & 30.1 & $37.1_{\text {II }}$ & 18.6 I & 30.8 & $17.3_{\mathrm{c}, \mathrm{d}}$ & $34.6 \mathrm{~b}$ & $52.9_{\mathrm{b}}$ & $46.0_{\mathrm{b}}$ & $20.1_{a}$ & 31.7 & 32.3 & 30.2 \\
\hline 1 - 3 times & $27.7_{* *}$ & $41.3 *$ & 34.6 & 33.0 & 28.2 & 35.6 & 34.6 & 35.3 & 36.0 & 33.8 & 31.7 & 35.4 & 33.1 \\
\hline 4 - 6 times & $23.3_{* *}$ & $14.0 *$ & 17.1 & 22.7 & 17.9 & 22.1 & 20.6 & 7.8 & $9.0_{\mathrm{b}}$ & $25.2_{a}$ & 20.6 & 17.7 & 19.8 \\
\hline 7 - 9 times & 4.4 & 4.2 & 3.4 & 6.2 & 5.1 & 5.8 & 3.7 & 2.0 & 1.0 & 6.5 & 4.8 & 2.3 & 5.8 \\
\hline $10+$ times & 12.6 & 10.5 & $7.8_{\mathrm{II}}$ & 19.6 I & $17.9_{\mathrm{d}}$ & $19.2_{\mathrm{c}, \mathrm{d}}$ & $6.5_{b}$ & $2.0_{\mathrm{a}, \mathrm{b}}$ & 8.0 & 14.4 & 11.1 & 12.3 & 11.0 \\
\hline \multicolumn{14}{|l|}{$\underline{\text { Fast casual }}$} \\
\hline 0 times & 34.0 & 35.7 & $42.0_{\text {II }}$ & 19.6. & 41.0 & $23.1_{d}$ & 34.6 & $52.9_{\mathrm{b}}$ & $64.0_{\mathrm{B}, \mathrm{C}}$ & $20.9_{\mathrm{A}}$ & $19.0_{\mathrm{A}}$ & 40.8 & 30.2 \\
\hline 1 - 3 times & 45.9 & 47.6 & 45.4 & 49.5 & 30.8 & 51.9 & 49.5 & 43.1 & $26.0_{\mathrm{B}, \mathrm{C}}$ & $59.0_{\mathrm{A}}$ & $52.4_{\mathrm{A}}$ & 43.8 & 48.8 \\
\hline 4 - 6 times & 11.3 & 13.3 & 9.8 & 17.5 & 20.5 & 16.3 & 9.3 & 3.9 & 6.0 & 14.4 & 17.5 & 12.3 & 12.2 \\
\hline 7 - 9 times & 3.1 & 1.4 & 2.0 & 3.1 & 2.6 & 1.9 & 3.7 & 0.0 & 3.0 & 1.4 & 3.2 & 2.3 & 2.3 \\
\hline $10+$ times & 5.7 & 2.1 & $1.0_{\text {II }}$ & $10.3_{\mathrm{I}}$ & 5.1 & 6.7 & 2.8 & 0.0 & 1.0 & 4.3 & 7.9 & $0.8_{\beta}$ & $6.4_{\alpha}$ \\
\hline \multicolumn{14}{|l|}{$\underline{\text { Casual dining }}$} \\
\hline 0 times & 25.8 & 29.4 & $31.2_{\mathrm{II}}$ & 19.6 & 35.9 & 18.3 & 29.0 & 35.3 & $52.0_{\mathrm{B}, \mathrm{C}}$ & $15.1_{\mathrm{A}}$ & $15.9_{\mathrm{A}}$ & $34.6_{\beta}$ & $22.1_{\alpha}$ \\
\hline 1 - 3 times & 52.8 & 54.5 & 52.2 & 56.7 & 38.5 & 61.5 & 53.3 & 51.0 & $39.0_{\mathrm{B}}$ & $66.9_{\mathrm{A}, \mathrm{C}}$ & $47.6_{\mathrm{B}}$ & 50.8 & 55.8 \\
\hline $4-6$ times & 13.8 & 13.3 & 12.7 & 15.5 & 23.1 & 13.5 & 13.1 & 7.8 & 8.0 & 14.4 & 20.6 & 11.5 & 15.1 \\
\hline 7 - 9 times & 3.8 & 1.4 & 2.4 & 3.1 & 2.6 & 1.9 & 2.8 & 3.9 & $0.0_{\mathrm{C}}$ & $1.4_{\mathrm{C}}$ & $9.5_{\mathrm{A}, \mathrm{B}}$ & 1.5 & 3.5 \\
\hline $10+$ times & 3.8 & 1.4 & 1.5 & 5.2 & 0.0 & 4.8 & 1.9 & 2.0 & 1.0 & 2.2 & 6.3 & 1.5 & 3.5 \\
\hline \multicolumn{14}{|l|}{ Fine dining } \\
\hline 0 times & 64.8 & 67.8 & $72.2_{\mathrm{II}}$ & $53.6_{I}$ & 66.7 & 56.7 & 70.1 & 76.5 & $86.0_{\mathrm{B}, \mathrm{C}}$ & $56.8_{\mathrm{A}}$ & $55.6_{\mathrm{A}}$ & $76.2_{\beta}$ & $58.7_{\alpha}$ \\
\hline 1 - 3 times & 25.2 & 26.6 & 23.9 & 29.9 & 20.5 & 30.8 & 24.3 & 23.5 & $11.0_{\mathrm{B}, \mathrm{C}}$ & $35.3_{\mathrm{A}}$ & $28.6_{\mathrm{A}}$ & $19.2_{\beta}$ & $30.8_{\alpha}$ \\
\hline 4 - 6 times & 5.7 & 4.2 & 3.4 & 8.2 & 12.8 & 4.8 & 4.7 & 0.0 & 2.0 & 5.0 & 9.5 & 3.8 & 5.8 \\
\hline 7 - 9 times & 0.6 & 0.7 & $0.0_{\text {II }}$ & $2.1_{\mathrm{I}}$ & 0.0 & 1.9 & 0.0 & 0.0 & 0.0 & 1.4 & 0.0 & 0.0 & 1.2 \\
\hline $10+$ times & 3.8 & 0.7 & $0.5_{\text {II }}$ & $6.2_{I}$ & 0.0 & 5.8 & 0.9 & 0.0 & 1.0 & 1.4 & 6.3 & 0.8 & 3.5 \\
\hline
\end{tabular}

${ }^{1}$ Significant differences are denoted by *, **, ${ }^{2}$ Significant differences are denoted by I, II, ${ }^{3}$ Significant differences are denoted by a, b, c, d, ${ }^{4}$ Significant differences are denoted by A, B, C, ${ }^{5}$ Significant differences are denoted by $\alpha, \beta$

The experiment in this study forced participants to make tradeoffs in perceived social responsibility amongst the different fast food options, thus, resulting in relative rankings of CSR (Table 4). Panera Bread was selected as the restaurant that was most socially responsible, given its relative size of mean preference share (19.8\%) followed by Subway (14.2\%) and Chick-fil-A (12.3\%). The restaurants perceived the least socially responsible with the lowest mean preference shares were McDonald's (4.7\%), KFC (4.6\%), and Taco Bell (4.1\%). While the specific preference share estimates are of interest for further analysis, the relative rankings of restaurants (as measured by preference shares) are themselves of practical significance. Given the vast array of marketing materials and consumer messaging being employed by restaurants, it is likely of interest within the fast food indus- 
try to understand the relative ranking of fast food restaurants (according to perceived CSR) by respondents.

The relationships amongst perceived social responsibility of the different fast food restaurants are shared in Table 5. Amongst those relationships, generally the sizes of preference shares for restaurants perceived to be "most" socially responsible negatively correlated with the sizes of preference shares for those restaurants that were perceived to be "least" socially responsible. This was the case with the sizes of preference shares for Panera Bread, Chipotle, Chick-fil-A, and Starbucks when correlated with the sizes of preference shares for all other restaurants, including each other. Restaurants perceived to be least socially responsible typically positively correlated with each other as did the relationships amongst sizes of preference shares for McDonald's, Wendy's, Burger King, Taco Bell, Dunkin’ Donuts, and KFC.

Responses to perceived social responsibility with respect to sample demographics are presented in Table 6. Being female was positively correlated with the size of preference share for Chipotle. Women more often gave higher preference share to Chipotle (relative to all other fast food options presented). Interestingly, respondent's membership in the 18 - 24 year age group positively correlated with the sizes of preference shares for Burger King and Chipotle, and negatively correlated with the size of preference share for Panera Bread. Being a

\begin{tabular}{|c|c|c|c|c|}
\hline \multirow[t]{2}{*}{ Value } & \multirow{2}{*}{$\begin{array}{c}\text { MNL } \\
\text { Coefficient }\end{array}$} & \multicolumn{2}{|c|}{ RPL Econometric Estimations } & \multirow{2}{*}{$\begin{array}{l}\text { RPL Mean Shares of } \\
\text { Preferences }\end{array}$} \\
\hline & & Coefficient & Standard Deviation & \\
\hline Subway & $0.7664^{* * *}(0.0569)$ & $1.1139 * * *(0.0848)$ & $1.2005^{* * *}(0.0824)$ & 0.1420 \\
\hline Panera Bread & $0.9400 * * *(0.0571)$ & $1.4454 * * *(0.0934)$ & $1.6578^{* * *}(0.0859)$ & 0.1978 \\
\hline Starbucks & $0.5192 * * *(0.0565)$ & $0.7468 * * *(0.1034)$ & $1.9549 * * *(0.0950)$ & 0.0984 \\
\hline Wendy's & $0.4859 * * *(0.0564)$ & $0.6606^{* * *}(0.0679)$ & $0.4282 * * *(0.0690)$ & 0.0902 \\
\hline Burger King & $0.1456 * * *(0.0561)$ & $0.1976^{* * *}(0.0688)$ & $0.6346 * * *(0.0697)$ & 0.0568 \\
\hline Taco Bell & $-0.0990 *(0.0562)$ & $-0.1400 * *(0.0649)$ & $0.0541 *(0.0851)$ & 0.0405 \\
\hline Dunkin’ Donuts & $0.2616^{* * *}(0.0562)$ & $0.3714(0.0671)$ & $0.2549 * *(0.1085)$ & 0.0676 \\
\hline KFC & $0.0151(0.0563)$ & $-0.0018 *(0.0652)$ & $0.2189 * *(0.1111)$ & 0.0465 \\
\hline Chick-fil-A & $0.6064 * * *(0.0566)$ & $0.9715^{* * *}(0.0973)$ & $2.1151^{* * *}(0.1040)$ & 0.1232 \\
\hline Chipotle & $0.4365^{* * *}(0.0565)$ & $0.6615^{* * *}(0.0928)$ & $1.7015^{* * *}(0.0786)$ & 0.0903 \\
\hline McDonald's & 0.00 & 0.00 & & 0.0467 \\
\hline
\end{tabular}

Statistical significance to the $1 \% * * *, 5 \% * *$, and $10 \% *$ levels.

Table 5. Correlations amongst perceived fast food restaurant social responsibility preference shares $(\mathrm{n}=302)$.
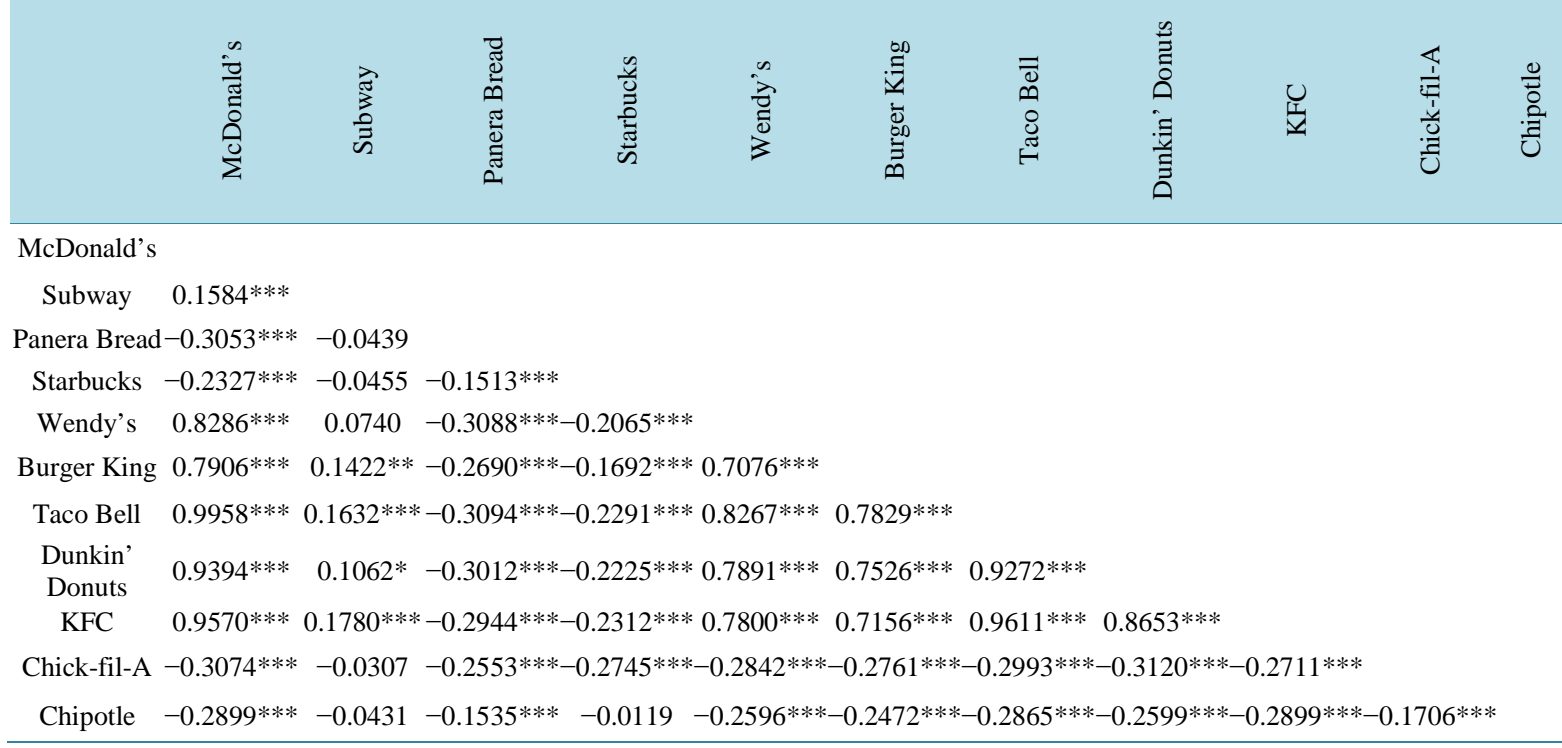

Statistical significance are indicated as $1 \% * * *, 5 \% * *$, and $10 \% *$ levels. 


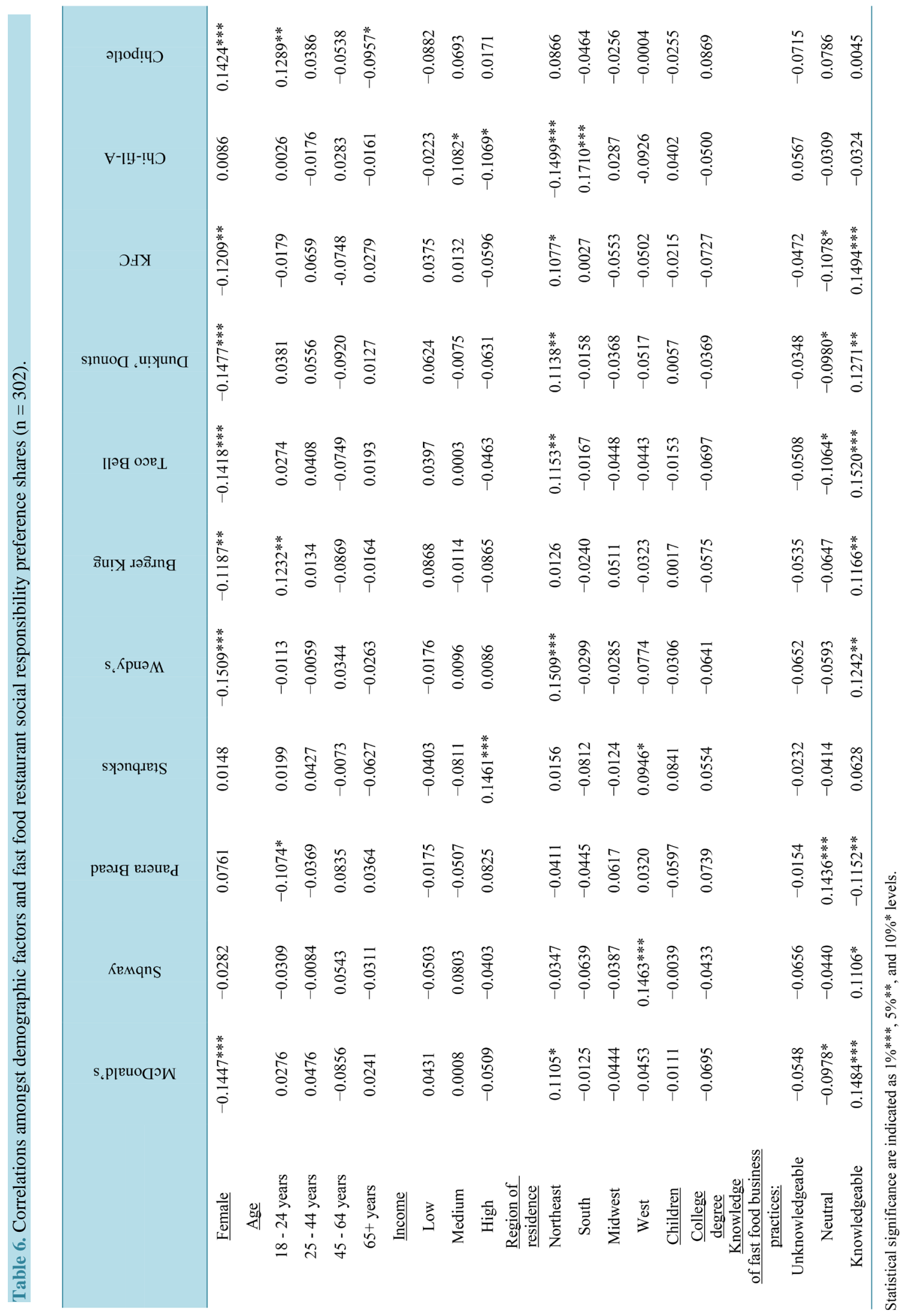


respondent aged 65 years or older was negatively correlated with the size of preference share for Chipotle.

Respondent membership in the high household income bracket positively correlated with the size of preference share (perceived social responsibility) for Starbucks, and negatively correlated with the size of preference share for Chick-fil-A, whereas, membership in the medium household income bracket was positively correlated However, knowledge of business practices was negatively correlated with the size of preference share for Panera Bread, which is surprising given that Panera Bread communicates about ethical sourcing, nutrition, and health in its advertisements and websites. It is possible that the finding may reflect lower national visibility, airing of commercials, or attention to Panera Bread's communications about its business practices relative to the other fast food restaurants for which a positive correlation was found between knowledge of practices and preference share for social responsibility. It is also possible that Panera Bread has sufficiently positive general reputation as to have high perceived CSR even when respondents admit unfamiliarity with fast food business practices in general.

Finally, the relationships amongst fast food restaurant visits, in terms of frequency, and perceived CSR of the prominent fast food restaurants were investigated (Table 7). Surprisingly few statistically significant correlations between frequency of visiting fast food restaurants and perceptions of CSR were found. Those results, though few, indicated that for respondents who indicated consuming fast food via take out or drive through there was a positively correlated relationship with the sizes of preference shares for Subway, Burger King, and KFC. Potentially, the lack of significance found between perceptions of CSR and frequency of consuming fast food would be due, at least in part, to the vast fast food options available in the U.S. marketplace. Reporting consumption of fast food, even frequent consumption, does not necessitate frequenting any of the restaurants studied here since many regional and local options exist in the marketplace. It is also entirely possible that given the level of impulse consumption of fast food that was observed in this study, social responsibility may not be foremost in the minds of those visiting such establishments or may be more of an after-thought.

\section{Conclusions}

While the frequency of eating out at fast food restaurants differed for respondents with or without children in the home, the correlation amongst this demographic factor and the relative perceptions of CSR of fast food restaurants was not significant. Participant knowledge of fast food business practices was significantly related to individuals' perceptions of CSR for the fast food restaurants investigated. This implies that marketing programs geared toward educating consumers may be valuable and have the potential to impact views of the restaurant if consumers feel more knowledgeable. This also supports Bronn and Vrioni's [8] finding that marketers must be genuine in their efforts and have a thorough understanding of their consumers' knowledge of the company and their products to be effective at using CSR or cause-related marketing. In the current era of high social media usage and availability of technology and information that can inform consumers, attaining and maintaining positive CSR remain both a challenge and opportunity for food corporations.

This analysis has several limitations which preclude the ability to determine specific reasons for respondents' perceived relative corporate social responsibility for different restaurants (beyond correlation relationships with basic demographics and fast food consumption). Consumption data, which is specific to each individual restau-

Table 7. Correlations amongst eating out frequency and food restaurant social responsibility preference shares $(n=302)$.

\begin{tabular}{|c|c|c|c|c|c|c|c|c|c|c|c|}
\hline & 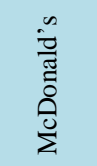 & \begin{tabular}{l}
$\vec{\pi}$ \\
3 \\
\multirow{3}{*}{}
\end{tabular} & 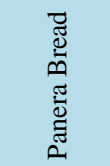 & 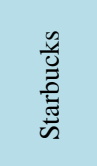 & $\sum_{0}^{\infty}$ & 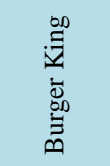 & 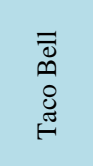 & 㓠泀 & $\underset{\underline{I}}{u}$ & 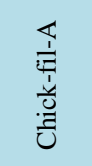 & 䒿 \\
\hline $\begin{array}{l}\text { Fast food-sit } \\
\text { down in } \\
\text { restaurant }\end{array}$ & 0.0113 & -0.0257 & -0.0002 & 0.0328 & 0.0018 & 0.0093 & 0.0096 & 0.0284 & 0.0230 & 0.0139 & -0.0092 \\
\hline $\begin{array}{l}\text { Fast food-take } \\
\text { out or drive } \\
\text { through }\end{array}$ & 0.0941 & $0.3974 * * *$ & -0.0804 & 0.0103 & 0.0324 & $0.0969 *$ & 0.0912 & 0.0779 & $0.1087^{*}$ & 0.0092 & -0.0538 \\
\hline
\end{tabular}

Statistical significance are indicated as $1 \%^{* * *}, 5 \%{ }^{* *}$, and $10 \% *$ levels. 
rant studied, if collected in future studies, would allow more in-depth analysis of whether an individual's familiarity with specific restaurant chains is a significant determinant in consumers' perceptions of CSR for fast food restaurants.

\section{References}

[1] U.S. Department of Agriculture, Economic Research Service (2016) Food Expenditures. http://ers.usda.gov/data-products/food-expenditures.aspx

[2] McDonald's (2016) Sustainability. http://www.aboutmcdonalds.com/mcd/sustainability.html

[3] Panera Bread (2016) Our Food Policy: Positive Impact. https://www.panerabread.com/en-us/our-beliefs/our-food-policy/positive-impact.html

[4] Wood, D.J. (1991) Corporate Social Performance Revisited. The Academy of Management Review, 16, 691-718.

[5] Sethi, S.P. (1979) A Conceptual Framework for Environmental Analysis of Social Issues and Evaluation of Business Response Patterns. The Academy of Management Review, 4, 64-74.

[6] Davis, K. (1973) The Case for and against Business Assumption of Social Responsibilities. The Academy of Management Journal, 16, 312-322. http://dx.doi.org/10.2307/255331

[7] Vogel, D. (2005) The Market for Virtue: The Potential and Limits of Corporate Social Responsibility. The Brookings Institution, Washington DC.

[8] Bronn, P.S. and Vrioni, A.B. (2001) Corporate Social Responsibility and Cause-Related Marketing: An Overview. International Journal of Advertising, 20, 207-222.

[9] Schroeder, M.J.A. (2003) Food Quality and Consumer Value: Delivering Food that Satisfies. Springer-Verlag, Berlin Heidelberg.

[10] Schroeder, M.J.A., and McEachern, M.G. (2005) Fast Foods and Ethical Consumer Value: A Focus on McDonald's and KFC. British Food Journal, 107, 212-224. http://dx.doi.org/10.1108/00070700510589503

[11] Cummins, A.M., Widmar, N.J.O., Croney C.C. and Fulton, J.R. (2016) Understanding Consumer Pork Attribute Preferences. Theoretical Economics Letters, 6, 166-177. http://dx.doi.org/10.4236/tel.2016.62019

[12] Wolf, C.A. and Tonsor, G.T. (2013) Dairy Farmer Policy Preferences. Journal of Agriculture and Resource Economics, 38, 220-234.

[13] Erdem, S., Rigby, D. and Wossink, A. (2012) Using Best-Worst Scaling to Explore Perceptions of Relative Responsibility for Ensuring Food Safety. Food Policy, 37, 661-670. http://dx.doi.org/10.1016/j.foodpol.2012.07.010

[14] Finn, A. and Louviere, J.J. (1992) Determining the Appropriate Response to Evidence of Public Concern: The Case of Food Safety. Journal of Public Policy and Marketing, 11, 12-25.

[15] Flynn, T.N. (2010) Valuing Citizen and Patient Preferences in Health: Recent Developments in Three Types of BestWorst Scaling. Expert Review of Pharmacoeconomics \& Outcomes Research, 10, 259-267. http://dx.doi.org/10.1586/erp.10.29

[16] Louviere, J.J. (1993) The Best-Worst or Maximum Difference Measurement Model: Applications to Behavioral Research in Marketing. Pheonix, Arizona.

[17] Lusk, J.L. and Briggeman, B.C. (2009) Food Values. American Journal of Agricultural Economics, 91, 184-196. http://dx.doi.org/10.1111/j.1467-8276.2008.01175.x

[18] Schwartz, S.H. (1992) Universals in the Content and Structure of Values: Theoretical Advances and Empirical Tests in 20 Countries. Advances in Experimental Social Psychology, 25, 1-65. http://dx.doi.org/10.1016/S0065-2601(08)60281-6

[19] Auger, P., Devinney, T.M. and Louviere, J.J. (2007) Using Best-Worst Scaling Methodology to Investigate Consumer Ethical Beliefs across Countries. Journal of Business Ethics, 70, 299-326. 